\title{
Two new species of Lepidiella (Diptera: Psychodidae: Psychodinae) from the Atlantic Rainforest of southeastern Brazil
}

\author{
Freddy Bravo ${ }^{1,3} \&$ Claudiney Biral dos Santos ${ }^{2}$
}

\author{
${ }^{1}$ Departamento de Ciências Biológicas, Universidade Estadual de Feira de Santana. Avenida Transnordestina, \\ 44036-900 Feira de Santana, BA, Brazil. \\ 2 Unidade de Medicina Tropical, Universidade Federal do Espírito Santo. Avenida Marechal Campos 1468, \\ 29040-090 Vitória, ES, Brazil. \\ ${ }^{3}$ Corresponding author. E-mail: fbravo@uefs.br
}

\begin{abstract}
Currently, the Neotropical genus Lepidiella Enderlein, 1937 comprises ten species, only one of them recorded from Brazil. In this paper, two new species of this genus are described from the Atlantic Rainforest of the state of Espírito Santo, Brazil. Lepidiella robusta sp. nov. can be distinguished from all known species by the relative size of the first flagellomere, twice as long the second. Lepidiella flabellata sp. nov. can be distinguished from all known species by the absence of cornicula, cercus with 17 tenacula and pair of inner parameres apically bifurcated. A diagnosis of Lepidiella (species with flagellomeres 1-11 barrel-shaped, bearing simple, unbranched ascoids; flagellomeres 12-14 smaller, without ascoids; wing with acute apex and $\mathrm{R}_{4}$ ending at tip; Rs not pectinated) and an identification key to males of the genus are provided.
\end{abstract}

KEY WORDS. Atlantic Rainforest; moth fly; Neotropical region; new taxa; taxonomy.

The Neotropical Lepidiella Enderlein, 1937 consists of ten species, only one of them known from Brazil, state of São Paulo (Bravo 2005). In this study, we describe two new species of Lepidiella from the Atlantic Rainforest of southeastern Brazil, and provide an identification key to the species of the genus.

\section{MATERIAL AND METHODS}

The specimens were collected with CDC light traps, cleared with $10 \% \mathrm{KOH}$ and mounted in Berlese's medium according to the methodology described by BARRETTO \& COUTINHO (1940). General morphological terminology follows that of McAlpine (1981). Terminology specific to the Psychodidae follows DuckHouse (1990). The specimens were deposited in the Coleção Entomológica Prof. Johann Becker do Museu de Zoologia da Universidade Estadual de Feira de Santana, Brazil (MZUEFS).

\section{TAXONOMY}

\section{Lepidiella Enderlein, 1937}

Lepidiella Enderlein, 1937: 89. Type-species: Lepidiella lanuginosa Enderlein, 1937: 89-90, by monotypy and original designation.

Syntomoza Enderlein, 1937: 88-89. Type-species: Syntomoza niveitarsis Enderlein, 1937: 89, by monotypy and original designation.

Kupara Rapp, 1945: 310. Type-species: Kupara albipeda Rapp, 1945: 311, by monotypy and original designation.
Diagnosis. Males: head with or without a pair of large, multilobed cornicula; vertex height on midline 2.0 or 3.0 times the width of eye bridge; antenna with 14 flagellomeres; flagellomeres 1-11 barrel-shaped, bearing simple, unbranched ascoids; flagellomeres 12-14 smaller, without ascoids; some species with first flagellomere 2.0 times as long as second; eye bridge of four facet rows, separated, connected by a " $\mathrm{V}$ " or " $\mathrm{Y}$ " inverted suture; wing with acute apex and $\mathrm{R}_{4}$ ending at tip; Rs not pectinated; gonocoxal apodemes fused, forming a bridge, narrow, plate-like, not extended anteriorly; cercus elongated with multiple tenacula; aedeagus symmetrical; parameres paired; epandrium with two foramina. Female similar to male except by: head with no cornicula; subgenital plate with small apical lobes.

Remarks. Two characters can be considered as putative synapomorphies of Lepidiella, the wing with pointed apex and the $\mathrm{R}_{4}$ ending at tip. This genus was included in the Pericomini Enderlein by QUATE (1996), one of the five tribes recognized by Duckhouse $(1985,1987)$ in the Psychodinae. The Pericomini form a major part of the psychodid fauna of the Holarctic region (Duckhouse 1987), but are poorly represented in the Neotropical region. Only two genera of this tribe are known from the Neotropics, the endemic Lepidiella and Pericoma Walker, 1856, a genus that is well represented in the Holarctic region and has four species described from the Neotropical region (Wagner 1993, Quate 1996). Quate (1963) suggested affinities between Lepidiella and Pericoma and Duckноuse (1974) between Lepidiella and Panimerus Eaton, 1913, but neither of 
the two proposals were tested because there are no phylogenetic analyses of Psychodinae or Pericomini.

Included species in Lepidiella: L. albipeda (Rapp, 1945), known from Panama and Nicaragua; L. amaliae (Collantes \& Martinez-Ortega, 1997), Nicaragua; L. cervi (Satchell, 1955), Saint Lucia in the eastern Caribbean Sea; L. lanuginosa Enderlein, 1937, Bolivia; L. matagalpensis (Colantes \& Martinez-Ortega, 1998), Nicaragua; L. monteverdica (Quate, 1996), Costa Rica; L. niveitarsis (Enderlein, 1937), Peru; L. pickring (Quate, 1999), Panama; L. spinosa Bravo, 2005, state of São Paulo, Brazil; L. zumbadoi (Quate, 1996), Costa Rica; L. flabellata Bravo \& Santos sp. nov. and L. robusta Bravo \& Santos sp. nov., both from state of Espírito Santo, Brazil.

\section{Key to males of Lepidiella Enderlein}

1. Head without cornicula .. 2

1 '. Head with multilobed cornicula ........................................ 3

2. Cercus with nine tenacula; pair of inner parameres not bifurcated L. spinosa

2 '. Cercus with 17 tenacula; pair of inner parameres apically bifurcated L. flabellata sp. nov.

3. Scape with apical lobe in the internal area . ... 4

3 '. Scape subcylindrical

4. First flagellomere long, two times the length of second ..... L. robusta sp. nov.

4 '. First flagellomere with the same length or slightly longer than the second one .. 5

5. Aedeagal apodeme broad in dorsal view, with the same width as the gonocoxite....

... 6

5'. Aedeagal apodeme narrow in dorsal view, narrower than the gonocoxite 7

6. Cornicula with three small lobes; aedeagus bifid with curved shafts, apices not ending in dorsal spiraliform tip; paramere spirally twisted L. albipeda

6'. Cornicula with five large lobes; aedeagus Y-shaped, apices ending in dorsal spiraliform tip; paramere not spirally twisted L. pickeringi

7. Scape two times the length of pedicel; cercus with 15 tenacula; aedeagus with two parallel shafts L. cervi

7'. Scape 3.5 times the length of pedicel; cercus with eight tenacula; aedeagus with two convergent shafts

L. monteverdica

8. Eyes separated by 1 facet row L. niveitarsis

8 '. Eyes separated by more than 2 facet rows ... 9

9. Radial fork at the same level of medial fork; first flagellomere twice the length of the second one L. lanuginosa

9'. Radial fork apical to medial fork; first flagellomere 1.3 times the length of the second one .. 10

10. Posterior margin of $\mathrm{C}$ (costa) more convex than anterior one . L. matagalpensis

$10^{\prime}$. Posterior margin of C straight, not convex .. L. zumbadoi

\section{Lepidiella flabellata sp. nov. Figs 1-6}

Type material. BRAzIL, Espírito Santo: municipality of Barra de São Francisco (18 $45^{\prime}$ S 4053’W), 20.IX.2009, Santos, C.B. leg., holotype male (MZUEFS). One paratype male, Espírito Santo, Pancas municipality, Córrego Ubá, $19^{\circ} 04^{\prime} \mathrm{S} 40^{\circ} 48^{\prime} \mathrm{W}$, 20.IX.2009, Santos, C.B. leg. (MZUEFS).

Diagnosis. Cornicula absent; scape subcylindrical; first flagellomere 1.1 times as long as second, spindle-shaped; veins $\mathrm{R}_{2+3}$ and $\mathrm{R}_{5}$ incomplete; presence of 17 tenacula; two pairs of parameres, external ones wider than internal ones, the latter with apex bifurcated.

Description. Holotype male. Length from thorax to posterior end of abdomen, $2.08 \mathrm{~mm}$. Head (Fig. 1). Subcircular, interocular suture V-shaped. Cornicula absent. Eye bridge of four facet rows, separated by a diameter of 2.0 facet diameters. Antenna incomplete (damaged) in the holotype and all paratypes. Scape 1.2 times as long as pedicel; subcylindrical, internal margin of scape not inflated and without long, apical bristles. First flagellomere 1.1 times as long as second; flagellomeres 1-13 spindle-shaped with digitiform ascoids. Palpus with four segments; relative length of palpomeres 1.0:1.6:1.8:2.0. Wing (Fig. 2). Length $1.68 \mathrm{~mm}$; maximum width $0.56 \mathrm{~mm} . \mathrm{R}_{2+3}$ not reaching Rs; $\mathrm{R}_{4}$ ending at tip; $\mathrm{R}_{5}$ not reaching $\mathrm{R}_{4}$; $\mathrm{CuA}$ incomplete at apex. Male terminalia. Cerci, gonocoxites and gonostyles with pilosity (Figs 3 and 5). Epandrium wider than long, with two foramina (Fig. 4). Tergite 10 digitiform, ending before apex of sternite 10, with micropilosity (Fig. 4). Sternite 10 with rounded apex and apical micropilosity (Fig. 4). Cercus digitiform with 17 tenacula (Fig. 11). Hypandrium lost in preparation. Gonocoxite cylindrical with internal area inflated, 0.5 times as long as gonostylus; gonostylus broad at base and tapering apically (Fig. 3). Aedeagus symmetrical, bifid, V-shaped (Fig. 6). Two pairs of parameres, external ones wider than internal ones, the latter with apex bifurcated (Fig. 6). Aedeagal apodeme 1.5 times as long as external paramere, narrow (Fig. 6).

\section{Lepidiella robusta sp. nov. Figs 7-12}

Type material. BrazIL, Espírito Santo: municipality of Barra de São Francisco (Córrego Vargem Alegre, 1847'S, 4051'W), 01.X.2008, Santos, C.B.leg., holotype male (MZUEFS). One paratype male, Espírito Santo, municipality of Brejetuba (Barra Córrego Santa Rita), 02.X.2010, Santos, C.B.leg. (MZUEFS).

Diagnosis. Cornicula present, 4-lobed; internal margin of scape inflated with group of long and apical bristles; first flagellomere 3.0 times as long as second one, cylindrical; veins $\mathrm{R}_{2+3}, \mathrm{R}_{5}$, and $\mathrm{M}_{2}$ incomplete; hypandrium strip-like, narrow; presence of 10 tenacula.

Description. Holotype male. Length from thorax to posterior end of abdomen, $2.66 \mathrm{~mm}$. Head (Fig. 7). Subcircular, 


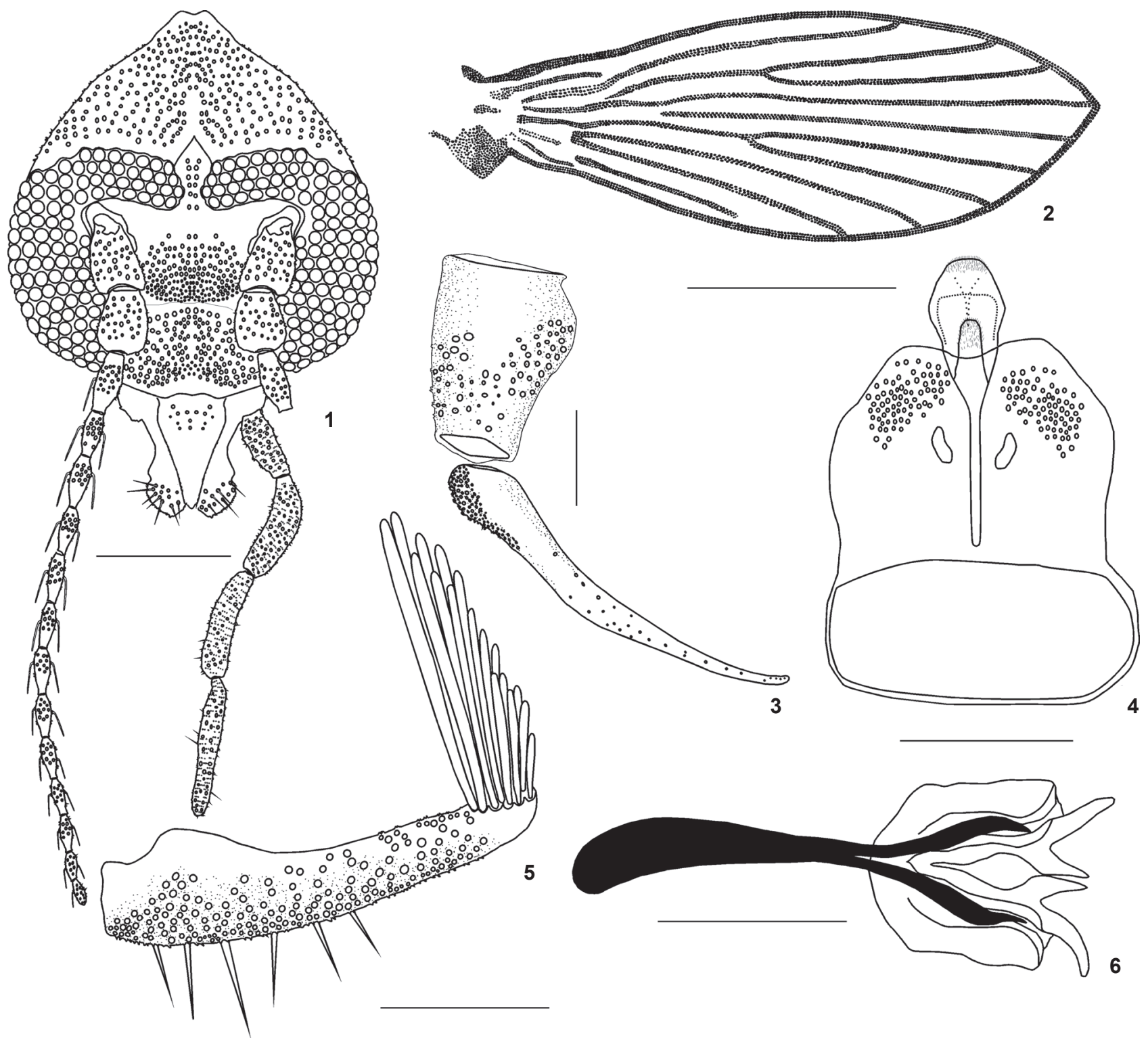

Figures 1-6. Lepidiella flabellata sp. nov., holotype male: (1) head; (2) wing; (3-6) male terminalia: (3) gonocoxite and gonostylus; (4) epandrium and sternite $X ;(5)$ cercus; (6) aedeagal apodeme and aedeagus. Scale bars: 1, 4, $6=0.10 \mathrm{~mm}, 2=0.50 \mathrm{~mm}, 3,5=0.05 \mathrm{~mm}$.

interocular suture V-shaped. Cornicula membranous, branched and densely clothed with scales. Eye bridge of four facet rows, separated by a diameter of 1.5 facet diameters. Antenna incomplete (damaged). Scape 3.0 times as long as pedicel; internal margin of scape inflated with group of long bristles, dusterlike. First flagellomere 3.0 times as long as second one, cylindrical; flagellomeres 2-13 spindle-shaped with digitiform ascoids. Palpus with four segments; relative length of palpomeres 1.0:1.7:2.2:3.0. Wing (Fig. 8). Length $1.78 \mathrm{~mm}$; maximum width $0.54 \mathrm{~mm}$. $\mathrm{R}_{2+3}$ not reaching Rs; $\mathrm{R}_{4}$ ending at tip; $\mathrm{R}_{5}$ not reaching $\mathrm{R}_{4} ; \mathrm{M}_{1}$ not reaching $\mathrm{M}_{2}$. Male terminalia. Cerci, gonocoxites and gonostyles with pilosity (Figs 10-12). Epandrium longer than wide, with two lateral foramina (Fig. 12). Cerci digitiform with 10 tenacula (Fig. 11). Hypandrium narrow, stripe-like (Fig. 9). Gonocoxite cylindrical, 0.5 times as long as gonostylus; gonostylus broad at base and tapering apically (Figs 9 and 10). Aedeagus symmetrical, bifid, V-shaped. Two pairs of parameres, external ones wider than internal ones (Fig. 9). Aedeagal apodeme with the same length of gonostylus, narrow (Fig. 9). 


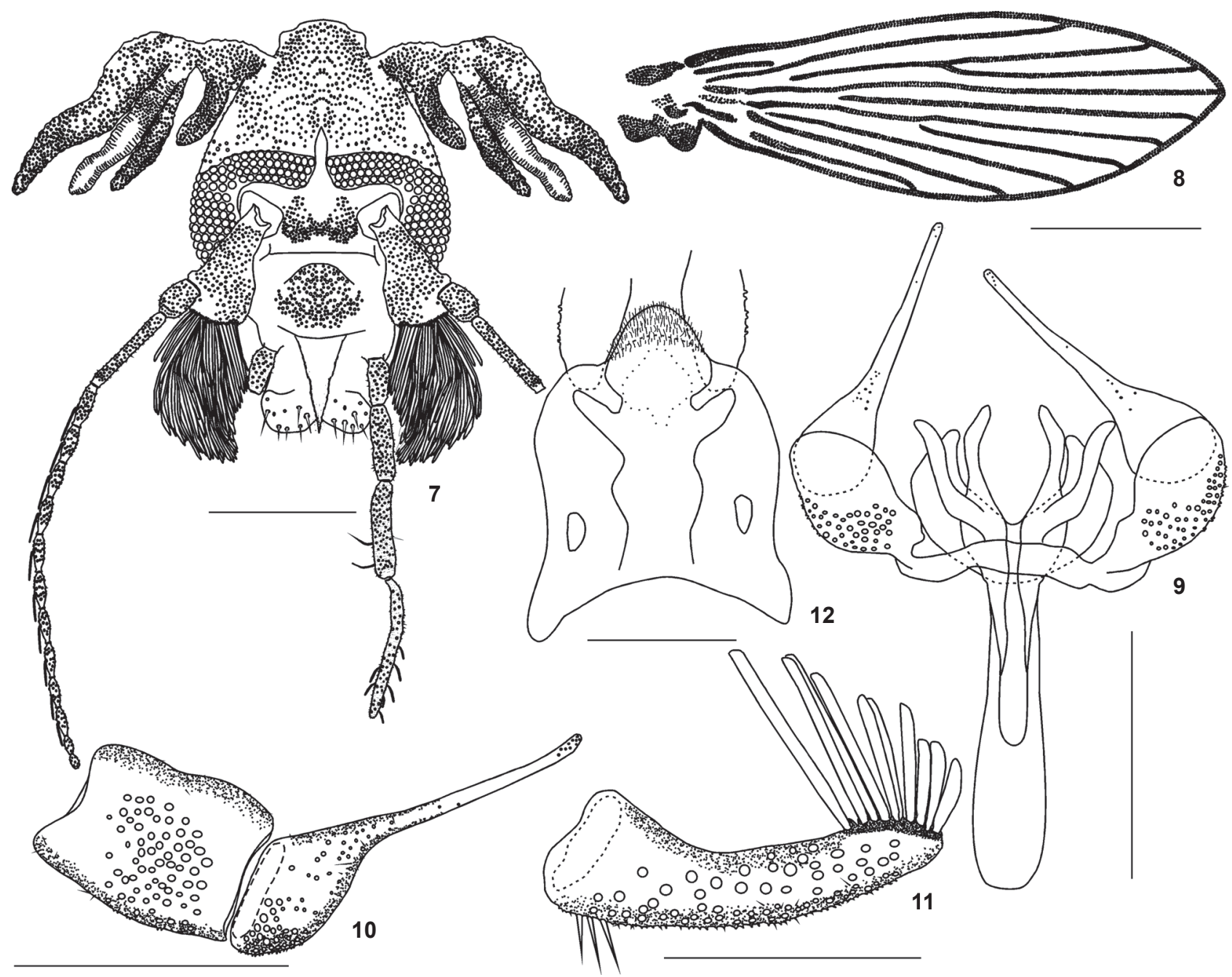

Figures 7-12. Lepidiella robusta sp. nov., holotype male: (7) head; (8) wing; (9-12) male terminalia: (9) dorsal view; (10) gonocoxite and gonostylus; (11) cercus; (12) epandrium and sternite X. Scale bars: $7=0.20 \mathrm{~mm}, 8=0.50 \mathrm{~mm}, 9-12=0.10 \mathrm{~mm}$.

\section{DISCUSSION}

Lepidiella robusta sp. nov. can be distinguished from all known species of the genus by the relative size of the first flagellomere, twice as long as the second. Lepidiella flabellata sp. nov. can be distinguished from congeners by a unique combination of characters: absence of cornicula, cercus with 17 tenacula and a pair of inner parameres apically bifurcated. Lepidiella amaliae is known only from two females from Nicaragua, so that it is necessary to consider other characters for comparing it with the new species herein described. Lepidiella amaliae can be differentiated by having the wing is wider than the wings of the two new species (width/length of the wing): L. amaliae (1.0:2.2); L. flabellata sp. nov. (1.0:2.6); L. robusta sp. nov. (1.0:2.8).

\section{ACKNOWLEDGMENTS}

FB has a research grant from CNPq (302120/2009-2) and received financial support from $\mathrm{CNPq}$ (471199/2009-5). To two anonymous reviewers for their useful comments on the manuscript.

\section{LITERATURE CITED}

Barretto, M.P. \& J.O. Coutinho. 1940. Processos de captura, dissecação e montagem de flebótomos. Anais da Faculdade de Medicina da Universidade de São Paulo 16: 173-187.

Bravo, F. 2005. Primeiro registro de Lepidiella Enderlein (Diptera, Psychodidae, Psychodinae) no Brasil e descrição de uma espécie nova. Revista Brasileira de Zoologia 22 (2): 490-493. 
Duckhouse, D.A. 1974. Redescription of the neotropical Psychodidae (Diptera, Nematocera) described by Rapp and Curran. Journal of Entomology (B) 43 (1): 55-62.

Duckhouse, D.A. 1985. A re-examination of Neomaruina (Diptera, Psychodidae), with observations on its life-history and affinities and redefinition of the tribe Psychodini. Annals of the Natal Museum 26: 601-620.

Duckhouse, D.A. 1987. A revision of Afrotropical Setomima, elucidation of their genealogical relationships and descriptions of other Afrotropical Psychodinae (Diptera: Psychodidae). Annals of the Natal Museum 28 (2): 231282.

Duckhouse, D.A. 1990. The Australasian genera of Pericomoid Psychodidae (Diptera) and the status of related Enderlein genera in the Neotropics. Invertebrate Taxonomy 3: 721746.

Enderlein, G. 1937. Klassification de Psychodiden (Dipt.). Deutsche entomologische Zeitschrift 1936: 81-112
McAlpine, J.F. 1981. Morphology and terminology: adults, p. 963. In: J.F. Mcalpine; B.V. Peterson; G.E. Shewell; H.J. Teskey; J.R. VocкеRотн \& D.M. Wood (Eds). Manual of Nearctic Diptera. Ottawa, Research Branch, Agriculture Canada, Monograph 27, vol. 1.

Quate, L.W. 1963. Review of G. Enderlein's non-Holarctic genera of Psychodidae and description of a new species (Diptera). Transactions of the Royal Entomological Society of London 115: 181-196.

Quate, L.W. 1996. Preliminary taxonomy of Costa Rican Psychodidae (Diptera), exclusive of Phlebotominae. Revista de Biologia Tropical 44 (Suppl. 1): 1-81.

Rapp, W.F. 1945. New Psychodidae from Barro Colorado Island. Journal of the New York Entomological Society 53: 309311.

Wagner, R. 1993. On a collection of Psychodidae (Diptera) by Dr. L. Botosaneanu from some Caribbean islands. Aquatic Insects 15: 109-127.

Submitted: 24.XI.2010; Accepted: 20.III.2011.

Editorial responsibility: Gabriel L.F. Mejdalani

ZOOLOGIA 28 (2): 264-268, April, 2011 